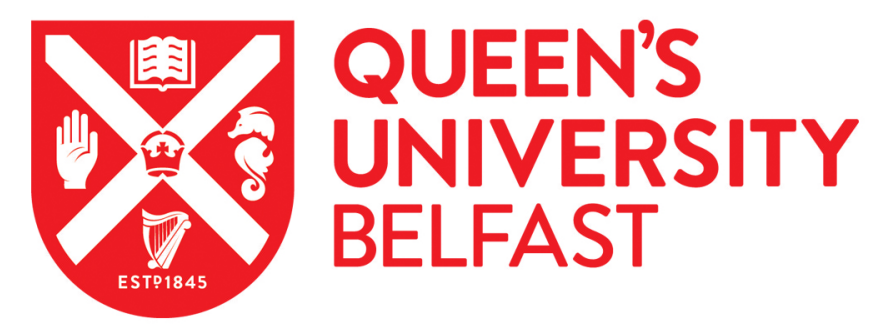

\title{
An investigation of the viscoelastic creep behaviour of basalt fibre reinforced timber elements
}

O'Ceallaigh, C., Sikora, K., McPolin, D., \& Harte, A. M. (2018). An investigation of the viscoelastic creep behaviour of basalt fibre reinforced timber elements. Construction and Building Materials, construction and building materials(187), 220-230. https://doi.org/10.1016/j.conbuildmat.2018.07.193

Published in:

Construction and Building Materials

Document Version:

Peer reviewed version

Queen's University Belfast - Research Portal:

Link to publication record in Queen's University Belfast Research Portal

Publisher rights

(C) 2018 Elsevier Ltd. All rights reserved.

This work is made available online in accordance with the publisher's policies. Please refer to any applicable terms of use of the publisher.

\section{General rights}

Copyright for the publications made accessible via the Queen's University Belfast Research Portal is retained by the author(s) and / or other copyright owners and it is a condition of accessing these publications that users recognise and abide by the legal requirements associated with these rights.

Take down policy

The Research Portal is Queen's institutional repository that provides access to Queen's research output. Every effort has been made to ensure that content in the Research Portal does not infringe any person's rights, or applicable UK laws. If you discover content in the Research Portal that you believe breaches copyright or violates any law, please contact openaccess@qub.ac.uk. 
See discussions, stats, and author profiles for this publication at: https://www.researchgate.net/publication/326781507

\section{An investigation of the viscoelastic creep behaviour of basalt fibre reinforced timber elements}

Article in Construction and Building Materials · October 2018

DOI: 10.1016/j.conbuildmat.2018.07.193

\section{CITATION}

1

4 authors:

Conan O'Ceallaigh

National University of Ireland, Galway

15 PUBLICATIONS 10 CITATIONS

SEE PROFILE

Karol S. Sikora

University of Wollongong in Dubai

27 PUBLICATIONS 94 CITATIONS

SEE PROFILE
READS

163

28. D.O. Mcpolin

44 PUBlicationS 328 CITATIONS

SEE PROFILE

A.M. Harte

National University of Ireland Galway

102 PUBLICATIONS 761 CITATIONS

SEE PROFILE

Some of the authors of this publication are also working on these related projects:

Commercialisation of Irish Cross Laminated Timber (CICLT) View project

Project "Polymer Concrete for Timber Composites" View project 


\title{
An Investigation of the Viscoelastic Creep Behaviour of Basalt Fibre Reinforced Timber
}

\section{Elements}

\author{
Conan O’Ceallaigh ${ }^{1}$, Karol Sikora ${ }^{2}$, Daniel McPolin ${ }^{3}$, Annette M. Harte ${ }^{1}$ \\ ${ }^{1}$ College of Engineering \& Informatics \& Ryan Institute, National University of Ireland Galway, University Rd., \\ Galway, Ireland. \\ ${ }^{2}$ Department of Civil Engineering, Xi'an Jiaotong-Liverpool University, Suzhou Dushu Lake Higher Education Town, \\ Jiangsu Province, P.R. China 215123. \\ ${ }^{3}$ School of Planning, Architecture and Civil Engineering, Queen's University Belfast, University Road, Belfast BT7 \\ $1 \mathrm{NN}, \mathrm{UK}$ \\ Email: conan.oceallaigh@nuigalway.ie,karol.sikora@xjtlu.edu.cn,d.mcpolin@qub.ac.uk, annette.harte@nuigalway.ie \\ Highlights \\ - Viscoelastic creep deflection of BFRP reinforced timber beams measured over a 75-week period. \\ - No significant reduction in relative viscoelastic deflection due to FRP reinforcement. \\ - Beneficial reduction in strain on the tension face due to reinforcement. \\ - $\quad$ Eurocode 5 Service Class 1 creep modification factors may be suitable for FRP reinforced beams.
}

ABSTRACT: An investigation was carried out to examine the effect of flexural reinforcement on the long-term behaviour of timber beams. Creep tests, utilising statistically matched groups, were performed under Service Class 1 conditions on reinforced and unreinforced beams loaded to a common maximum compressive stress of $8 \mathrm{MPa}$. As flexural reinforcement resulted in a reduction in the timber tensile stresses, the viscoelastic tensile strains in the reinforced members were found to be significantly lower than in the unreinforced beams. It was found that the viscoelastic relative creep deflection was governed by the stress level in the timber and the reinforcement had an insignificant effect. It is concluded that current creep modification factors in Eurocode 5 may be suitable for the design of reinforced timber elements under Service Class 1 conditions.

KEY WORDS: BFRP; Engineered wood products; Reinforced timber; Sitka spruce; Viscoelastic creep.

\section{INTRODUCTION}

Structural timber products have been shown to have benefitted with regard to stiffness and ultimate load capacity when reinforced with FRP (Fibre Reinforced Polymer) materials of a superior stiffness. The short-term behaviour of these reinforced elements is relatively well understood. The addition of reinforcement can delay tension failure in timber flexural elements and utilise the additional capacity of the timber in the compression zone resulting in much more consistent 
behaviour as well as a significant increase in flexural stiffness [1-9]. However, the long-term or creep behaviour of such members has received less attention. Accurate prediction of the long-term performance of timber elements is of crucial importance to structural engineers when designing timber structures as timber is particularly susceptible to large creep deformations when stressed for long periods of time.

Creep effects in timber elements can be divided into two main categories, namely, viscoelastic creep and mechanosorptive creep. The viscoelastic creep component is defined as the deformation with time at constant stress and under constant environmental conditions, which is typical of indoor conditions. Under variable environmental conditions, additional mechano-sorptive creep and swelling/shrinkage behaviour occurs. The mechano-sorptive creep effect has been shown to dramatically accelerate the rate of creep in a loaded timber element and is defined as a deformation due to the interaction between stress and moisture content change due to variable environmental conditions [10-13]. Eurocode 5 [14] provides modification factors which allow design engineers to account for both viscoelastic and mechano-sorptive creep behaviour of solid timber members and engineered wood products. Currently, there are no guidelines on how to account for the influence of reinforcement on the creep response of reinforced timber elements. The reasons for this are partly due to a lack of knowledge, particularly related to the long-term performance of such reinforcement systems. To date only a small number of studies have investigated creep behaviour in reinforced timber and further work in this area is required to enable the development of harmonised design rules for structural engineering applications. This paper focuses on establishing the influence of reinforcement on the viscoelastic creep of reinforced timber beams.

\subsection{Viscoelastic Creep Behaviour of Timber}

For many structural applications, the most important mechanical property of timber is its resistance to deflection, including both elastic and creep deflection. The contribution of creep deflection to the total deflection is generally much more significant in the case of timber structures to those made of steel or concrete. The creep behaviour of timber also more complex as it is a function not only of timber but also environmental conditions, which change the moisture content of the material. When stressed in a constant climate condition, a timber element undergoes an instantaneous elastic deflection followed by viscoelastic creep behaviour with time. Under this constant climate condition, the level of viscoelastic creep depends on the stress level, temperature and moisture content of the timber. Senft \& Suddarth [15] examined small specimens $\left(41.3\right.$ x 50.8 x $\left.203.2 \mathrm{~mm}^{3}\right)$ of Sitka spruce (Picea sitchensis) under compression load at stress levels of 10, 20, 40 and $60 \%$ of ultimate strength for load durations up to twenty days. The moisture content remained constant throughout to exclude the mechano-sorptive effect and focus solely on viscoelastic creep. They found that the viscoelastic creep behaviour increases with increasing stress levels and significantly, they found that creep deformation can occur at stress 
levels as low as $10 \%$ of ultimate strength. It was also reported that, at higher stress levels $(>55 \%)$, specimens are susceptible to creep rupture resulting in failure $[15,16]$. Similarly, an increase in temperature has been shown to result in higher viscoelastic creep deformations. Davidson [17] performed creep tests on three different species at a series of constant temperatures. It was shown that the rate of creep increased slightly with increasing temperature from $20^{\circ} \mathrm{C}$ to $50{ }^{\circ} \mathrm{C}$. The magnitude of viscoelastic creep has been also shown to depend on the moisture content of the timber $[10,11,18]$. In a study by Hering and Niemz [19], the viscoelastic behaviour of European beech timber elements subjected to four-point bending was investigated and the longitudinal creep compliance at three different moisture contents $(8.14 \%, 15.48 \%$ and $23.2 \%)$ was examined. Each timber specimen was loaded to approximately $25 \%$ of the ultimate bending strength for a period of approximately $200 \mathrm{hr}$ and the viscoelastic creep behaviour was found to increase linearly with increasing moisture content.

Another study designed to examine if the rate of creep eventually decreases towards a creep limit was performed by Hunt [20]. Experimental creep tests on solid timber elements were carried out in a carefully controlled environment over a 13week period. Creep functions were matched to these experimental test results and to creep test results by Gressel [21] over a much longer period of time (8 years). The curves were extrapolated to estimate the viscoelastic creep after 50 years under sustained load. No evidence was found to suggest a viscoelastic creep limit exists in timber when stressed in a constant climate condition. This demonstrates the potential for timber elements to deform throughout their service life and demonstrates the importance of understanding its behaviour.

\subsection{Viscoelastic Creep Behaviour in Reinforced Timber}

When timber elements are reinforced, the behaviour of the elements can be greatly altered. The short-term or instantaneous elastic behaviour of reinforced elements has been investigated by many authors and significant improvements in stiffness and ultimate moment carrying capacity have been demonstrated [1,3,7-9,22]. More ductile behaviour can be achieved when modest proportions of reinforcement are utilised in strategic locations. Reinforcing the tension zone of timber elements can delay tension failure and utilise the additional capacity of the timber in the compression zone. A limited number of studies have focused on the long-term or viscoelastic creep behaviour of FRP reinforced timber elements. Plevris and Triantafillou [23] performed long-term creep tests on carbon fibre reinforced polymer (CFRP) reinforced beams under three-point bending. There was a relatively small sample size of three beams, one unreinforced control beam and two reinforced beams with two different area reinforcement ratios of $1.18 \%$ and $1.65 \%$, respectively. The tests were carried out under constant climate conditions and similar loads were applied to each beam. This resulted in different stress levels in the timber. It was determined from the experimental results, that the creep behaviour of the FRP-reinforced timber elements was primarily dominated by stress within the timber. 
In a study by Yahyaei-Moayyed and Taheri [24], the creep performance of southern yellow pine (SYP) and Douglas fir

91 (DF) timber beams reinforced with aramid fibre reinforced polymer (AFRP) was examined. These creep tests were carried out in an uncontrolled climate over a period of 800 hours and it is noted that the applied loads (P) were not the same for the unreinforced and reinforced beams. When comparing one SYP unreinforced $(\mathrm{P}=4.85 \mathrm{kN})$ with one SYP reinforced beam $(\mathrm{P}=4.40 \mathrm{kN})$ there appeared to be a reduction in creep deflection, but it was not clear if this reduction was due to different stress levels within the timber or the presence of the AFRP reinforcement. The reduced load on the reinforced beam led to a lower stress level within the timber when compared to the unreinforced beam making comparisons difficult. Interestingly when one unreinforced DF beam $(\mathrm{P}=5.60 \mathrm{kN})$ and one reinforced DF beam $(\mathrm{P}=5.76 \mathrm{kN})$ were compared, there was a slightly higher load on the reinforced beam and a similar creep deflection was observed. The timber stress levels in both the unreinforced and reinforced beams were more comparable in this case. There was also an influence of the uncontrolled climate condition in this study and possible swelling/shrinkage or mechano-sorptive creep deformations as a result of the minor fluctuations in moisture content.

Davids et al. [25] performed long-term creep tests on six unreinforced and six reinforced $7 \mathrm{~m}$ long Douglas fir and western hemlock glulam beams in a sheltered environment with controlled temperature and uncontrolled relative humidity. A proportion of the beams were reinforced with glass fibre reinforced polymer (GFRP) plate with two percentage area reinforcement ratios, namely, $1.1 \%$ and $3.3 \%$. While the laboratory tests demonstrated the effectiveness of the GFRP reinforcement in reducing the elastic deformation between the unreinforced beams and the reinforced beams, a difference between the creep deformation of the unreinforced elements and the GFRP reinforced elements is only seen at the higher reinforcement level. It is noted by Davids et al. [25] that the effectiveness of FRP reinforcement on reducing creep cannot be inferred from the test data due to the different load and associated stress levels in the timber in addition to the uncontrolled relative humidity during the test.

The creep behaviour of a loaded timber element has been shown to be heavily influenced by the stress level within the timber. When reinforced, the flexural stiffness of the timber beam is altered and stress distribution through the cross-section is affected. In an effort to reduce the difference in stress distribution between unreinforced and reinforced beams, beams should be loaded to a common maximum stress, similar to that performed by Kliger et al. [22] who carried out mechanosorptive creep tests on beams loaded to a common maximum compressive stress.

\subsection{Objectives of the Current Study}

The objective of this study is to investigate the influence of flexural reinforcement on the long-term viscoelastic behaviour of timber beams in a constant climate. As has been shown, the viscoelastic behaviour of timber is influenced by many 
factors such as the timber mechanical properties, moisture content, temperature and the stress level in the timber. To

120 characterise the influence of the reinforcement on the viscoelastic response, a test procedure was designed to minimise the 121 differences in timber properties, environmental conditions and stress level between unreinforced and reinforced beam 122 groups. Groups of beams with statistically matched flexural stiffness were tested in a customised test rig in a constant 123 climate over a 75-week period. Different loads were applied to the reinforced and unreinforced beams to minimise the 124 difference in bending stress levels. This provides a common basis for comparative studies. The findings of this study are 125 intended to contribute to the database of knowledge required to develop future design guidelines for reinforced timber 126 beams.

\section{$127 \quad 2$ EXPERIMENTAL PROCEDURE}

\section{$128 \quad 2.1 \quad$ Introduction}

129 The glued laminated beams used in the test programme were manufactured using Irish-grown Sitka spruce. The lay-up of 130 each glued laminated beam was designed to allow beams of approximately equal stiffness to be manufactured. A proportion 131 of the beams were reinforced with basalt fibre reinforced polymer (BFRP) rods in the bottom tensile lamination. These 132 unreinforced and reinforced beams were subject to short and long-term flexural testing in a controlled, constant 133 environment.

\section{$134 \quad 2.2 \quad$ Glulam Materials and Manufacture}

135 The Sitka spruce timber used in this study was grade C16. Sourced in Ireland, this timber has an average rotation length of $13630-40$ years [26] and is characterised as a fast-growing, low-density timber which when subjected to flexural loading 137 generally fails in tension due to the presence of knots [3,27]. However, when combined to create a composite element such 138 as a glued laminated beam, the capacity of this softwood timber may be greatly increased [5,7]. Each lamination was 139 strength graded using a mechanical grading machine and ranked in descending order of modulus of elasticity. The lay-up 140 of forty beams was designed using the machine grading results and manufactured in the Timber Engineering Laboratory at the National University of Ireland, Galway. The design process minimised the variation in mean modulus of elasticity of all forty beams. The beams were laminated by applying a 1:1 phenol resorcinol formaldehyde adhesive and clamping to a pressure of $0.6 \mathrm{~N} / \mathrm{mm}^{2}$ for 24 hours in accordance with EN 14080 [28]. The beams comprise four laminations with each beam measuring approximately $98 \mathrm{~mm}$ x $125 \mathrm{~mm}$ x $2300 \mathrm{~mm}$. Each beam was conditioned in a constant climate condition at a temperature of $20 \pm 2{ }^{\circ} \mathrm{C}$ and at a relative humidity of $65 \pm 5 \%$, prior to reinforcement. 
147 less attention in previous studies but has the potential to rival more commonly used fibres in load bearing applications in 148 the construction industry [29-32]. Twenty of the beams were reinforced with two $12 \mathrm{~mm}$ BFRP rods positioned in two 149 circular routed grooves in the bottom tensile lamination. The grooves were sized to accommodate the BFRP rod plus a 2 $150 \mathrm{~mm}$ glue line, as seen in Fig. 1. A two-part structural epoxy adhesive was used to bond the reinforcement to the timber. 151 The BFRP rod manufacturer reported a tensile strength of $1000+\mathrm{N} / \mathrm{mm}^{2}$ and a modulus of elasticity of $45+\mathrm{GPa}$ [33] but 152 experimental tensile tests on six test specimens in accordance with ISO 10406-1 [34] demonstrated a mean tensile strength of $905 \mathrm{~N} / \mathrm{mm}^{2}$ and a mean modulus of elasticity of $50.7 \mathrm{GPa}$. The beams were placed a conditioning chamber with a temperature of $20 \pm 2{ }^{\circ} \mathrm{C}$ and with a relative humidity of $65 \pm 5 \%$, where they remained to cure for a period of 3 weeks prior to flexural testing.

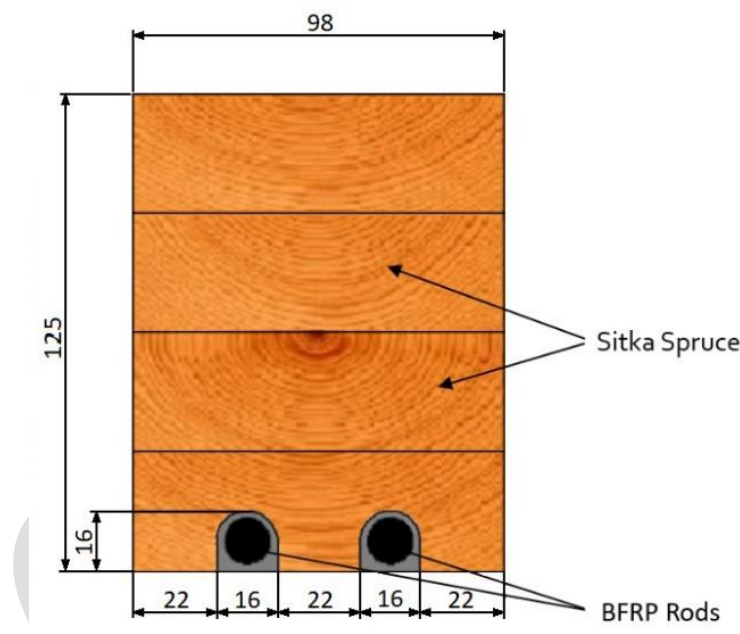

Fig. 1. Cross-section of a Sitka spruce manufactured beam reinforced with two BFRP rods in the tensile lamination.

\subsection{Short-term Testing}

Each beam underwent a short-term four-point bending test in accordance with EN 408 [35] to evaluate the flexural stiffness.

The load was applied through a hydraulic actuator at a rate of $0.15 \mathrm{~mm} / \mathrm{s}$ to a maximum load of approximately $40 \%$ of the ultimate failure load to ensure that the elastic limit was not exceeded. The deflection at the midspan of the beam was measured using two LVDTs, one for determining the local stiffness and the other for the global stiffness.

This short-term test was performed on all beams in their unreinforced state to determine their initial flexural stiffness.

The test results allowed two groups, statistically equal in terms of bending stiffness, to be created. One group was subsequently reinforced. The creation of matched groups reduces the difference in the beams due to the variability inherent within timber and provides a reliable basis for comparative studies. Once reinforced, the four-point flexural test was 
repeated. The test set-up remained the same throughout allowing the percentage increase in bending stiffness to be calculated.

\section{$2.4 \quad$ Long-term Testing}

\subsubsection{Test Frame Design and Instrumentation}

There is no standardised method for examining the creep behaviour of timber beams. As a result, different test methods and test frames have been reported in the literature. The majority of authors implement a four-point bending test set-up $[13,22,24,25,27]$; however, in some cases, a three-point bending test set-up [23] or a uniformly distributed load across the whole length of the member have been used [36].

In this study, the creep test frame was designed to implement a four-point flexural test set-up. The geometrical constraints of this set-up were in accordance with the short-term flexural test prescribed in EN 408 [35]. The creep test frame was designed to accommodate eighteen beams simultaneously loaded to a constant bending stress to induce viscoelastic creep behaviour with time. The constant bending stress is achieved by applying a dead load, M (steel plates $250 \times 100 \times 10 \mathrm{~mm}^{3}$ ), through a lever-arm mechanism. An example of this mechanism on a single beam can be seen in Fig. 2. The lever-arm is free to rotate about the fulcrum. The lever-arm length, $\mathrm{a}_{2}$ (distance from the load to the fulcrum), is adjustable and dead load, M, can be added or subtracted as necessary to achieve a desired bending stress. The flexural load, F, applied at a distance $\mathrm{a}_{1}$ from the fulcrum is equal to the dead load, $\mathrm{M}$, multiplied by the ratio $\mathrm{a}_{2} / \mathrm{a}_{1}$.
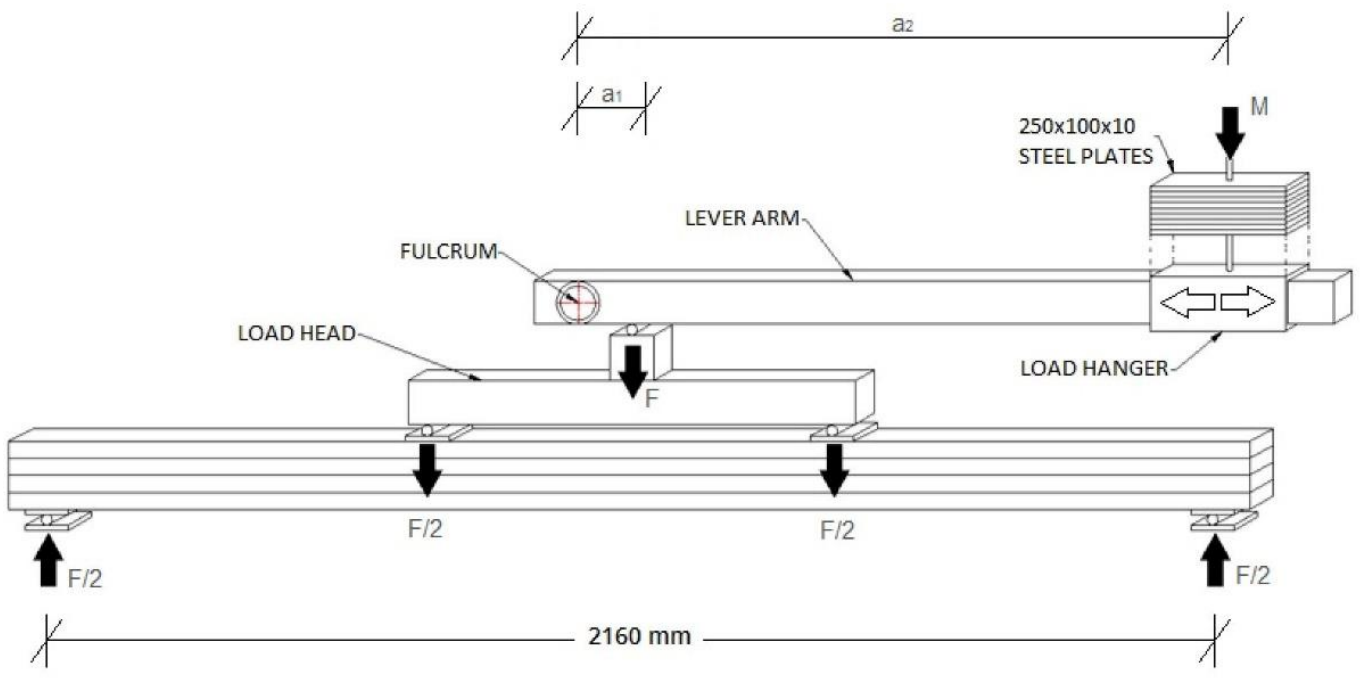

Fig. 2. Creep test beam loaded in four-point bending using an adjustable lever-arm mechanism.

The beam mid-span deflection was measured using a Mitutoyo displacement dial gauge with an accuracy of $0.01 \mathrm{~mm}$ and the mid-span longitudinal strain on the tension and compression faces was measured using electrical resistance strain 
gauges (TML type PLW-60-11) specially designed for long-term use on timber elements. The strain gauges on the tension face of the reinforced beams were adhered to the timber surface of the beam situated between two routed grooves which house the BFRP rods as seen in Fig. 3.

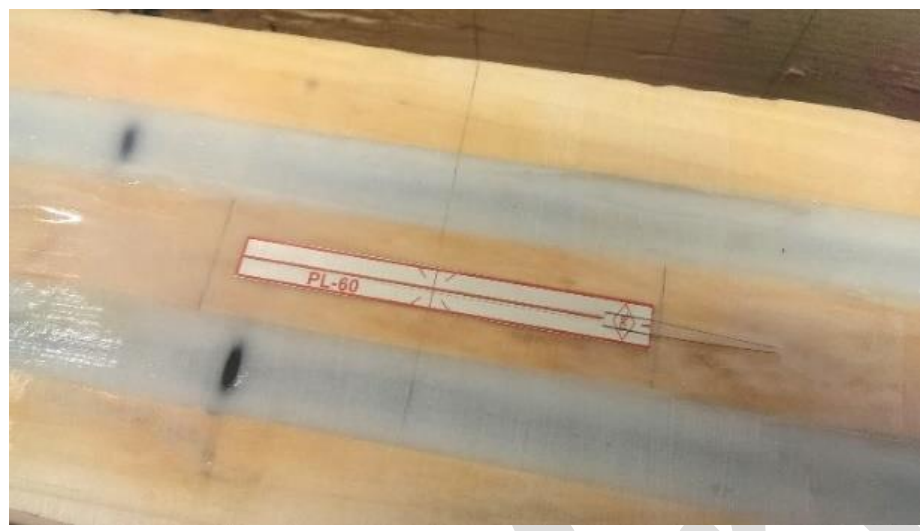

Fig. 3. Strain gauge orientated longitudinally between two BFRP rods on the tension face of a reinforced beam.

These long-term strains were monitored using a Campbell Scientific data acquisition system, which recorded strains every five minutes during the early stages of the test. This frequency was slowly reduced with time to its current frequency of one hour. The beams are tested in a controlled climate chamber at a temperature of $20 \pm 2{ }^{\circ} \mathrm{C}$ and at a relative humidity of $65 \pm 5 \%$ throughout, which coincides with Service Class 1 conditions as defined in Eurocode 5 [14].

\subsubsection{Loading Procedure}

As the aim of the tests is to determine the influence of the reinforcement on the creep performance, the applied loading for the tests was chosen to minimise the difference in the timber stress levels between the unreinforced and reinforced beams. Two different loading scenarios were investigated: the beams are loaded to the same maximum compressive stress level (Case A) or to the same load level (Case B). Analytical modelling of the stress distribution in the unreinforced and reinforced beams was undertaken assuming linear elastic behaviour. For the analysis, it was assumed that elastic moduli of the timber laminations and the BFRF rods were $8000 \mathrm{~N} / \mathrm{mm}^{2}$ and $50000 \mathrm{~N} / \mathrm{mm}^{2}$, respectively.

For Case A, it was assumed that each beam was loaded to a maximum compressive bending stress of $8.0 \mathrm{~N} / \mathrm{mm}^{2}$. For the reinforced beam, the load required to achieve this maximum compressive stress was $6333 \mathrm{~N}$ as seen in Table 1. For this load, the maximum timber tensile stress is $7.08 \mathrm{~N} / \mathrm{mm}^{2}$. The maximum tensile stress in the unreinforced beam is 8.00 $\mathrm{N} / \mathrm{mm}^{2}$, which is $13 \%$ higher than the reinforced beam. For Case B, a load of $6333 \mathrm{~N}$ applied to the unreinforced beam results in maximum tensile and compressive timber stresses of $8.75 \mathrm{~N} / \mathrm{mm}^{2}$, which are higher by $23.6 \%$ and $9.3 \%$, respectively, than the corresponding stresses in the reinforced beam, as shown in Table 1. As the differences in the stress distributions is smaller for Case A, it was decided to apply a maximum bending stress of $8 \mathrm{MPa}$ on the compression face of each beam in the test programme. The applied load chosen corresponds to approximately $25-30 \%$ of the ultimate load 
of the unreinforced glued laminated beam which was chosen to produce measurable deflections in a reasonable time scale

212 without causing failure in the specimen. This common maximum stress level is an essential component of this test 213 procedure as it minimises the influence of stress distribution on the long-term response of both the unreinforced and 214 reinforced beams. This allows for comparisons to be made between creep in unreinforced and reinforced beams and the 215 influence of the BFRP reinforcement to be quantified. To achieve this common maximum stress level, different loads were 216 required for each beam with greater loads on average required on the reinforced beams.

Table 1. Comparison between maximum tensile and compressive timber stresses

\begin{tabular}{cccccc}
\hline Beam State & Load (N) & $\begin{array}{c}\text { Max. Tensile } \\
\text { Stress }\left(\mathrm{N} / \mathrm{mm}^{2}\right)\end{array}$ & $\begin{array}{c}\text { Percentage } \\
\text { Increase (\%) }\end{array}$ & $\begin{array}{c}\text { Max. Compressive } \\
\text { Stress (N/mm²) }\end{array}$ & $\begin{array}{c}\text { Percentage } \\
\text { Increase (\%) }\end{array}$ \\
\hline Reinforced & 6333 & 7.08 & $0.0 \%$ & 8.00 & $0.0 \%$ \\
Unreinforced (Case A) & 5792 & 8.00 & $13.0 \%$ & 8.00 & $0.0 \%$ \\
Unreinforced (Case B) & 6333 & 8.75 & $23.6 \%$ & 8.75 & $9.3 \%$ \\
\hline
\end{tabular}

\subsection{Statistical Methods}

230 Statistical methods have been implemented to create the matched groups described above using the test results for all beams prior to reinforcement. Once reinforced, similar statistical methods were utilised to examine the influence of the 
reinforcement on both the short- and long-term behaviour of the reinforced beams. Student's t-tests were carried out to

233 compare the means of each matched group to one another. When performing a Student's t-test, each sample or group being 234 compared should follow a normal distribution and the variance of each sample or group must be considered. Shapiro-Wilk tests were performed on each group to assess normality. The null hypothesis of this test assumes the sample is normally distributed and a p-value greater than the chosen significance level indicates that the hypothesis that the data came from a normally distributed sample cannot be rejected. Once normality or a normally distributed sample cannot be rejected,

238 Levene's test was performed to examine the homogeneity of the group or sample variances. Levene's test is an inferential test statistic implemented to assess the equality of variances for two or more groups or samples. The null hypothesis of this test assumes the sample variances are equal. If the p-value is greater than the chosen significance level, the null hypothesis is accepted and it is concluded that there is an insignificant difference between the variances of all samples tested. In this study, all statistical tests are carried out to a significance level of $0.95(\alpha=0.5)$. In each sample studied, normality could not be rejected and each group was assumed to follow a normal distribution. When comparing groups using Levene's test, a proportion of the groups had equal variances and a proportion had unequal variances. For equal variances, Student's ttest was implemented as it assumes equal variances. In the case of unequal variances, an adapted version of Student's ttest known as Welch's t-test or unequal variances t-test was used to compare the means of both groups.

\subsection{Short-term Test Results}

The mean flexural stiffness results and associated standard deviation for beams in their respective groups in an unreinforced state are presented in Table 2 and Fig. 5. The mean local and global flexural stiffness of the Unreinforced Group are $1.40 \times 10^{11} \mathrm{Nmm}^{2}$ and $1.28 \times 10^{11} \mathrm{Nmm}^{2}$, respectively, and the mean local and global flexural stiffness of the Reinforced Group are $1.46 \times 10^{11} \mathrm{Nmm}^{2}$ and $1.36 \times 10^{11} \mathrm{Nmm}^{2}$, respectively. Statistical Student's t-tests have demonstrated that there is no evidence to suggest the mean of each group is not equal. The reinforced group was then reinforced and the short-term test results for the reinforced beam group are presented in Table 3. The mean local and global bending stiffnesses for beams in their unreinforced and reinforced states are given together with the associated standard deviations. The percentage increase in stiffness is also determined. A mean increase in local bending stiffness of $16.30 \%$ for a moderate percentage reinforcement ratio of $1.85 \%$ was observed. There was a mean increase of $8.8 \%$ in global bending stiffness. There is a significant standard deviation of $5.9 \%$ associated with this global stiffness measurement.

Table 2. Mean flexural stiffness results and associated standard deviation for beams in their respective groups in an unreinforced state

\begin{tabular}{cc}
\hline Unreinforced Group & Reinforced Group \\
\hline
\end{tabular}




\begin{tabular}{cccccc}
\hline Beam No. & $\begin{array}{c}\text { Global Stiffness, } \\
\mathrm{EI}_{\text {Global }}\left(\mathrm{Nmm}^{2}\right)\end{array}$ & $\begin{array}{c}\text { Local Stiffness, } \\
\mathrm{EI}_{\text {Local }}\left(\mathrm{Nmm}^{2}\right)\end{array}$ & Beam No. & $\begin{array}{c}\text { Global Stiffness, } \\
\mathrm{EI}_{\text {Global }}\left(\mathrm{Nmm}^{2}\right)\end{array}$ & $\begin{array}{c}\text { Local Stiffness, } \\
\mathrm{EI}_{\text {Local }}\left(\mathrm{Nmm}^{2}\right)\end{array}$ \\
\hline Beam 5 & $1.29 \mathrm{E}+11$ & $1.57 \mathrm{E}+11$ & Beam 1 & $1.32 \mathrm{E}+11$ & $1.20 \mathrm{E}+11$ \\
Beam 6 & $1.27 \mathrm{E}+11$ & $1.31 \mathrm{E}+11$ & Beam 2 & $1.40 \mathrm{E}+11$ & $1.44 \mathrm{E}+11$ \\
Beam 9 & $1.39 \mathrm{E}+11$ & $1.45 \mathrm{E}+11$ & Beam 3 & $1.62 \mathrm{E}+11$ & $1.61 \mathrm{E}+11$ \\
Beam 11 & $1.32 \mathrm{E}+11$ & $1.38 \mathrm{E}+11$ & Beam 4 +11 \\
Beam 15 & $1.03 \mathrm{E}+11$ & $1.14 \mathrm{E}+11$ & Beam 7 & $1.48 \mathrm{E}+11$ & $1.67 \mathrm{E}+11$ \\
Beam 16 & $1.30 \mathrm{E}+11$ & $1.41 \mathrm{E}+11$ & Beam 8 & $1.26 \mathrm{E}+11$ & $1.53 \mathrm{E}+11$ \\
Beam 17 & $1.24 \mathrm{E}+11$ & $1.48 \mathrm{E}+11$ & Beam 10 & $1.38 \mathrm{E}+11$ & $1.38 \mathrm{E}+11$ \\
Beam 18 & $1.28 \mathrm{E}+11$ & $1.31 \mathrm{E}+11$ & Beam 12 & $1.37 \mathrm{E}+11$ & $1.39 \mathrm{E}+11$ \\
Beam 21 & $1.52 \mathrm{E}+11$ & $1.65 \mathrm{E}+11$ & Beam 13 & $1.20 \mathrm{E}+11$ & $1.44 \mathrm{E}+11$ \\
Beam 22 & $1.28 \mathrm{E}+11$ & $1.43 \mathrm{E}+11$ & Beam 14 +11 & $1.68 \mathrm{E}+11$ \\
Beam 23 & $1.46 \mathrm{E}+11$ & $1.59 \mathrm{E}+11$ & Beam 19 & $1.25 \mathrm{E}+11$ & $1.33 \mathrm{E}+11$ \\
Beam 27 & $1.15 \mathrm{E}+11$ & $1.13 \mathrm{E}+11$ & Beam 24 & $1.52 \mathrm{E}+11$ & $1.40 \mathrm{E}+11$ \\
Beam 29 & $1.33 \mathrm{E}+11$ & $1.49 \mathrm{E}+11$ & Beam 26 & $1.42 \mathrm{E}+11$ & $1.51 \mathrm{E}+11$ \\
Beam 33 & $1.16 \mathrm{E}+11$ & $1.33 \mathrm{E}+11$ & Beam 28 & $1.40 \mathrm{E}+11$ & $1.51 \mathrm{E}+11$ \\
Beam 34 & $1.42 \mathrm{E}+11$ & $1.58 \mathrm{E}+11$ & Beam 30 & $1.21 \mathrm{E}+11$ & $1.31 \mathrm{E}+11$ \\
Beam 35 & $1.26 \mathrm{E}+11$ & $1.40 \mathrm{E}+11$ & Beam 31 & $1.20 \mathrm{E}+11$ & $1.35 \mathrm{E}+11$ \\
Beam 39 & $1.22 \mathrm{E}+11$ & $1.24 \mathrm{E}+11$ & Beam 32 & $1.35 \mathrm{E}+11$ & $1.35 \mathrm{E}+11$ \\
Beam 40 & $1.13 \mathrm{E}+11$ & $1.35 \mathrm{E}+11$ & Beam 36 & $1.27 \mathrm{E}+11$ & $1.27 \mathrm{E}+11$ \\
\hline Mean & $1.28 \mathrm{E}+11$ & $1.40 \mathrm{E}+11$ & & $1.36 \mathrm{E}+11$ & $1.46 \mathrm{E}+11$ \\
Std. Dev. & $1.18 \mathrm{E}+10$ & $1.42 \mathrm{E}+10$ & & $1.27 \mathrm{E}+10$ & $1.22 \mathrm{E}+10$ \\
\hline
\end{tabular}

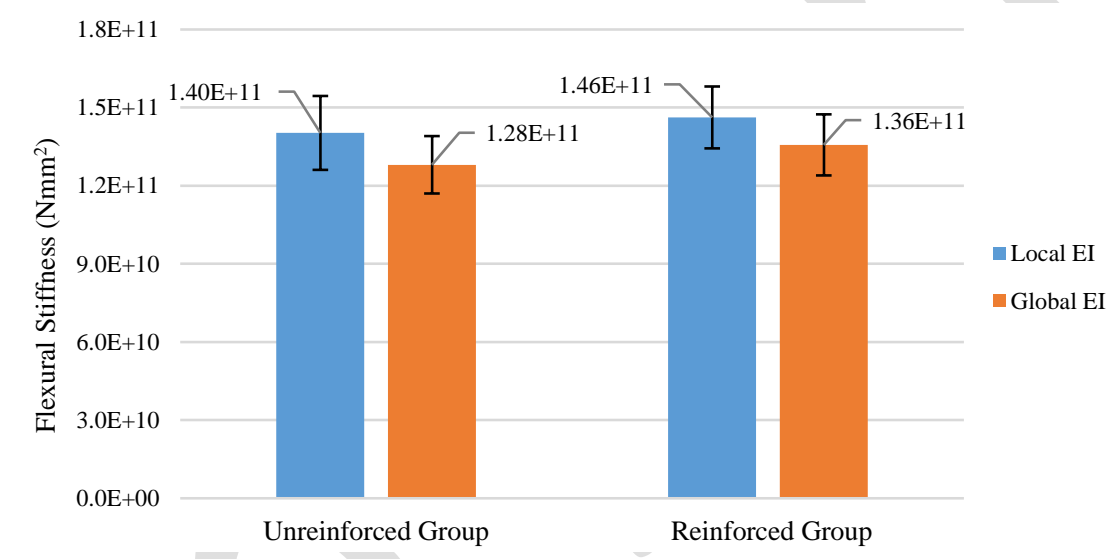

262 Fig. 5. Mean and standard deviation short-term local and global flexural stiffness $\left(\mathrm{Nmm}^{2}\right)$ results of beam groups in their unreinforced 263 state.

264 Table 3. Short-term local and global flexural stiffness results of the reinforced group beams in their unreinforced and reinforced state.

\begin{tabular}{ccccc}
\hline Stiffness $\left(\mathrm{Nmm}^{2}\right)$ & No. & Unreinforced & Reinforced & $\begin{array}{c}\text { Percentage Increase } \\
(\%)\end{array}$ \\
\hline $\mathrm{EI}_{\text {Local }}\left(\mathrm{x} 10^{11}\right)$ & 20 & $1.46(.120)^{*}$ & $1.69(.119)$ & $16.30(3.66)$ \\
$\mathrm{EI}_{\text {Global }}\left(\mathrm{x} 10^{11}\right)$ & 20 & $1.36(.123)$ & $1.47(.113)$ & $8.80(5.90)$ \\
\hline *Mean Values (Std. Deviation) & & &
\end{tabular}

\subsection{Long-term Test Results}

267 The long-term deflection and strain measurements over a 75-week test period are presented. Eighteen beams (nine 268 reinforced and nine unreinforced) were tested under a common maximum compression stress in a controlled constant 269 climate. The long-term deflection test results are expressed in terms of both total deflection and relative creep $\left(C_{R}\right)$ 270 deflection, which is defined as the deflection at time $t$, expressed as a proportion of the instantaneous elastic deflection as seen in Equation (1) [37]. 


$$
C_{R}(t)=\frac{w(t)}{w_{0}}
$$

where $C_{R}=$ relative creep, $w_{0}=$ instantaneous deflection and $w(t)=$ deflection at time, $t$.

274 As mentioned previously, for serviceability limit state design, Eurocode 5 [14] provides deformation modification factors $\left(k_{d e f}\right)$ for different service classes in order to account for creep effects. The service classes correspond to predefined environmental conditions and the $k_{\text {def }}$ factor is used to increase the instantaneous elastic deflection of the designed element to account for creep effects. Equation (2) describes the relationship between $k_{d e f}$ and relative creep.

$$
k_{\text {def }}\left(t-t_{0}\right)=\frac{w(t)-w\left(t_{0}\right)}{w\left(t_{0}\right)}=C_{R}(t)-1
$$

The total measured long-term strain results comprise the instantaneous elastic strain due to the application of the dead load and the viscoelastic creep strain with time as shown in Equation (3).

$$
\varepsilon_{T}=\varepsilon_{e}+\varepsilon_{v e}
$$

where $\varepsilon_{T}=$ total measured strain, $\varepsilon_{e}=$ elastic strain and $\varepsilon_{v e}=$ viscoelastic strain.

Assuming linear behaviour, the viscoelastic strain component is found by subtracting the instantaneous elastic strain component from the total measured strain. The mean total measured strain data and viscoelastic strain data for the unreinforced and reinforced beams over the 75-week test period are presented.

\subsubsection{Long-term Deflection Results}

The unreinforced beam group consists of nine beams, seven of which, are monitored with displacement dial gauges. The mid-span deflection for these seven beams are given in Fig. 6. Beam $27(9.068 \mathrm{~mm})$ and Beam $34(6.674 \mathrm{~mm})$ have the highest and lowest total deformation (instantaneous elastic deformation + viscoelastic creep deflection) after 75 weeks, respectively. This is as expected as they have the lowest and highest bending stiffness, respectively, when measured during short-term flexural tests. 


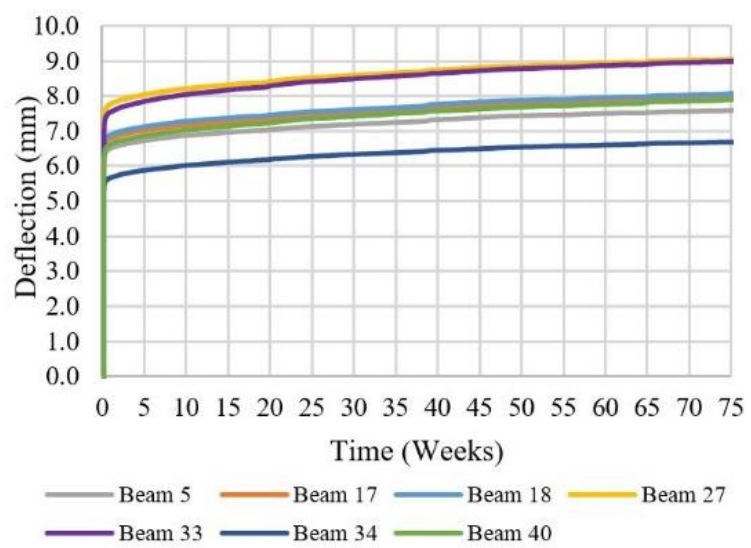

Fig. 6. Unreinforced deflection results.

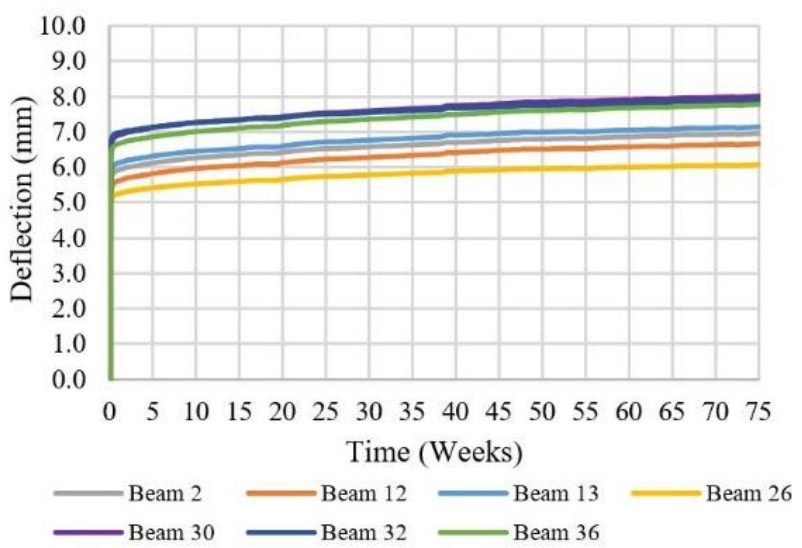

Fig. 7. Reinforced deflection results.

The reinforced beam group consists of nine beams. Seven of these beams are monitored with displacement dial gauges.

The mid-span deflection for these seven beams are given in Fig. 7. Beam 30 (8.022 mm) and Beam 26 (6.072 mm) have the highest and lowest total deflection after 75 weeks, respectively. Beam 30 and Beam 26 also had the lowest and highest bending stiffness, respectively, when measured during short-term flexural tests. The variability in the total deflection results within each matched group can be seen in Fig. 6 and Fig. 7. The average unreinforced bending stiffness of each group was shown to be statistically equal from short-term test data. To compare the deflection results of the unreinforced and reinforced groups and observe the effect of reinforcement, the average deflection for each beam group is shown in Fig. 8 . After 75 weeks, the mean total deflection in the unreinforced beam group $(8.032 \mathrm{~mm})$ is $10.69 \%$ greater than the reinforced beams group $(7.219 \mathrm{~mm})$.
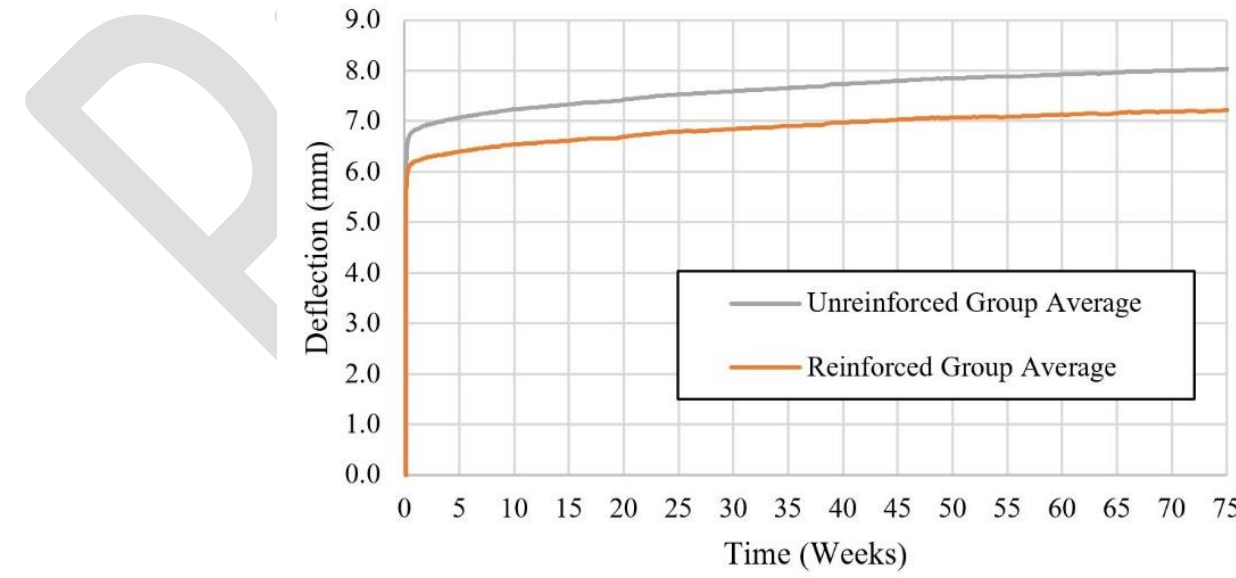

Fig. 8. Unreinforced and Reinforced group average deflection results.

Fig. 9 presents the average relative creep deflection results with time for the unreinforced and reinforced groups. Although there is a reduction in the overall deflection in the reinforced beam group due to the FRP reinforcement $(10.69 \%)$, very similar creep behaviour is observed between the measured relative creep deflections of both groups. This indicates that the 
reduction in total deflection observed in the reinforced group is primarily due to the lower instantaneous elastic deflection due to the increased stiffness provided by the reinforcement. The mean relative creep deflections and corresponding standard deviations of both groups are also plotted in Fig. 9 at a series of time points over the test period. For clarity, the results of the unreinforced and reinforced groups at the similar time points are offset from one another. Statistical Student's t-tests were performed at a series of time points throughout the test and the results are presented in Table 4.

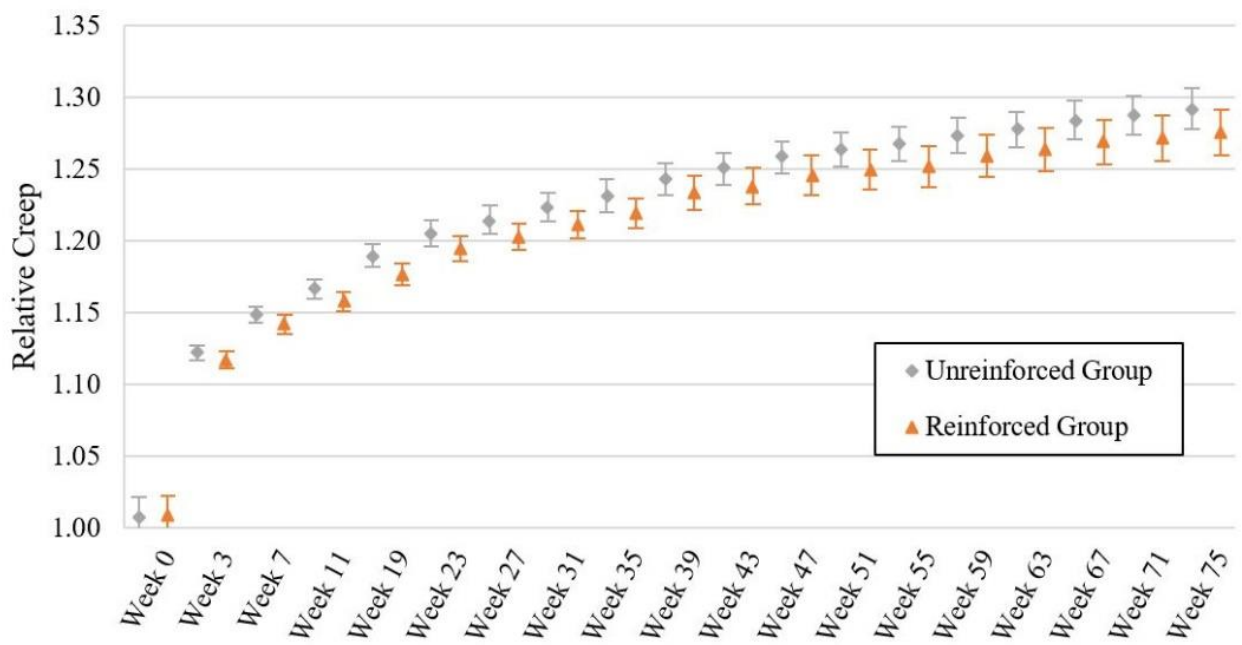

314 Fig. 9. Unreinforced and Reinforced average and standard deviation results at a series of time points throughout the 75-week test 315 period.

316 The percentage difference between the mean relative creep results of the unreinforced and reinforced group show that this difference is increasing with time. During the initial weeks (Week 0 to Week 19) the trend indicated a significant difference in the creep behaviour of unreinforced and reinforced beams was developing as seen in Table 4; however, this period was associated with a relatively high rate of creep deformation and after this point the statistical tests indicate an insignificant difference between the mean results of both groups. Although after 75 weeks of creep testing there is a reduction in the total deflection $(10.69 \%)$ in the reinforced group, there is less than $1.30 \%$ difference between the mean relative creep deflections of both groups at the same time point. A statistical analysis of the group means has shown that there is no statistically significant reduction in viscoelastic creep deflection in FRP reinforced beams when compared to unreinforced beams under similar bending stresses and constant climate conditions.

Table 4. Average relative creep deflection (standard deviation) of the unreinforced and reinforced groups at a series of time points.

\begin{tabular}{lccccccc}
\hline Group & Week 0 & Week 3 & Week 11 & Week 19 & Week 35 & Week 51 & Week 75 \\
\hline Unreinforced & $1.008(0.014)$ & $1.122(0.005)$ & $1.166(0.007)$ & $1.190(0.008)$ & $1.231(0.011)$ & $1.263(0.012)$ & $1.292(0.014)$ \\
Reinforced & $1.009(0.014)$ & $1.117(0.006)$ & $1.158(0.007)$ & $1.177(0.007)$ & $1.219(0.010)$ & $1.250(0.014)$ & $1.275(0.016)$ \\
\hline Percentage Diff. & $0.07 \%$ & $0.43 \%$ & $0.76 \%$ & $1.10 \%$ & $1.00 \%$ & $1.08 \%$ & $1.27 \%$ \\
Student's t-test & Not Sig. & Not Sig. & Sig. & Sig. & Not Sig. & Not Sig. & Not Sig. \\
p-Value & 0.9222 & 0.1330 & 0.0337 & 0.0085 & 0.0560 & 0.0702 & 0.0663 \\
\hline
\end{tabular}


The longitudinal strain has been measured on the tension and compression faces of seven unreinforced and seven reinforced beams. The mean total strain measurements from the tension and compression faces of the unreinforced and reinforced beam groups are presented in Fig. 10. The strain gauge measurements on the compression faces are similar when both beam groups are compared. The reinforced beam group experiences slightly less strain than the unreinforced beam group. In contrast, the difference between the strains measured on the tension face of each beam group is more significant. The reinforced beams experience $24.5 \%$ less strain on average after 75 weeks. This difference is as a result of the rod reinforcement and its position within the tensile lamination of each reinforced beam.

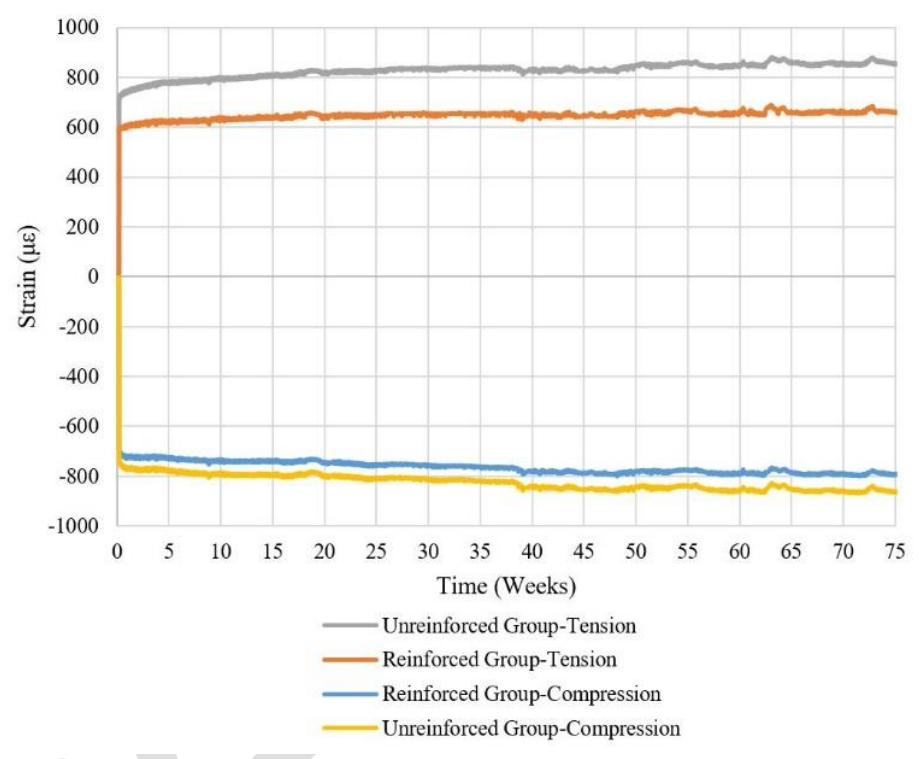

Fig. 10. Mean total strain results on the tension and compression face of the unreinforced and reinforced beam groups $\left(\varepsilon_{\mathrm{T}}=\varepsilon_{\mathrm{e}}+\varepsilon_{\mathrm{ve}}\right)$.

To isolate the viscoelastic strain, the instantaneous elastic strain component has been subtracted from the total strain component of each individual beam. The mean viscoelastic strain results are presented in Fig. 11. Similar mean strains are observed on the compression faces of both the unreinforced and reinforced beams groups indicating a similar stress and creep rate within both beam groups. In comparison, the mean strains on the tension face are larger for the unreinforced group than the reinforced group. The presence of the reinforcement causes a reduction in the timber tensile stresses as seen in and therefore a lower creep rate is expected (Table 1). It is important to note that the controlled climate chamber remained at a constant temperature of $20 \pm 2{ }^{\circ} \mathrm{C}$ and at a constant relative humidity of $65 \pm 5 \%$ throughout the duration of the test and that there was no additional effects due to mechano-sorptive creep or swelling/shrinkage of the timber. 


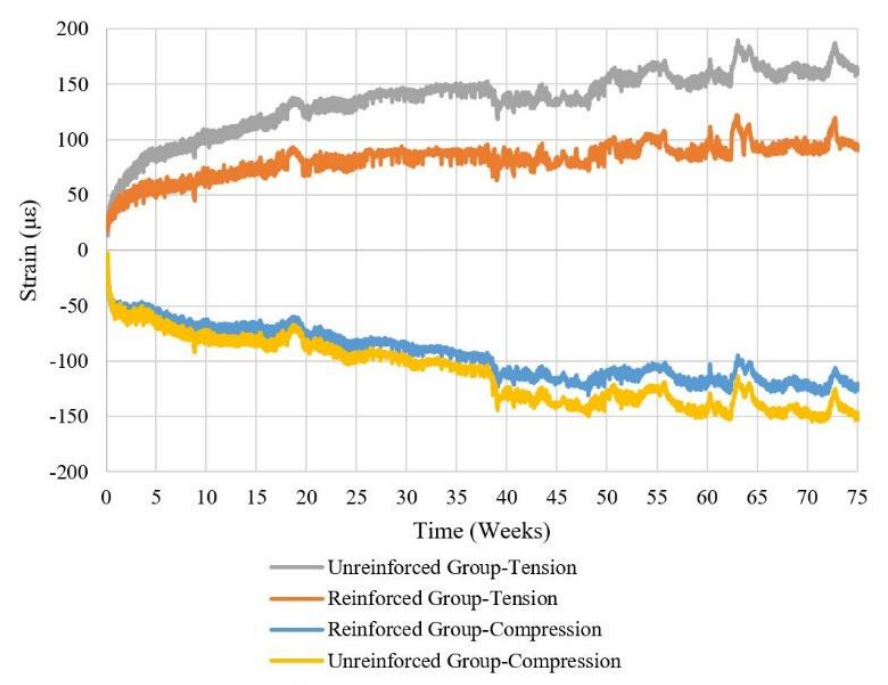

347 Fig. 11. Mean viscoelastic strain $(\mu \varepsilon)$ results on the tension and compression face of the unreinforced and reinforced beam groups $\left(\varepsilon_{\mathrm{ve}}\right)$.

348 To examine the significance of differences in viscoelastic strain on the compression face, the values at a series of time

349 points are presented in Fig. 12 and Table 5. The mean viscoelastic strain results in Fig. 12 show similar trends in both the unreinforced and reinforced groups. Again, there is a slightly higher standard deviation associated with the unreinforced group beams. In Table 5, the difference between the mean of each group is not statistically significant at any point throughout the test. The percentage difference ranges from $8.23 \%$ at week 3 to a maximum of $20.80 \%$ at week 67 . The trend is generally increasing throughout the test; however, there is no evidence to suggest the mean viscoelastic strain measured on the compression face of the unreinforced and reinforced groups is different. This shows that a similar bending stress on the compression face results in a similar creep rate within the timber.

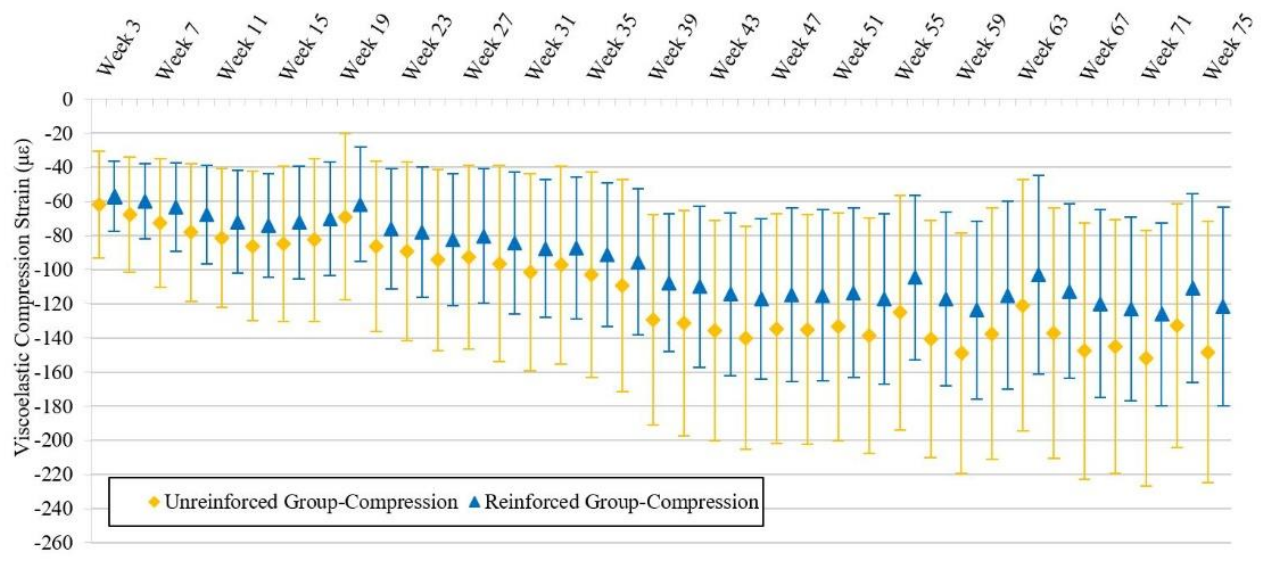

Fig. 12. Mean and standard deviation of the viscoelastic strain $(\mu \varepsilon)$ measured on the compression face of the unreinforced and reinforced groups at a series of time points $\left(\varepsilon_{\mathrm{ve}}\right)$. 
Table 5. Average viscoelastic strain (standard deviation) on compression face of unreinforced and reinforced groups at a series of time points $\left(\varepsilon_{\mathrm{ve}}\right)$.

\begin{tabular}{lccccccc}
\hline Group-Compression & Week 3 & Week 11 & Week 19 & Week 35 & Week 51 & Week 67 & Week 75 \\
\hline Unreinforced & $-61.94(31.19)$ & $-83.69(42.60)$ & $-69.02(48.70)$ & $-102.95(60.41)$ & $-133.48(66.80)$ & $-147.71(75.05)$ & $-148.23(76.71)$ \\
Reinforced & $-57.05(20.66)$ & $-73.42(30.39)$ & $-61.81(33.53)$ & $-91.24(42.06)$ & $-113.66(49.66)$ & $-119.87(55.11)$ & $-121.71(58.21)$ \\
\hline Percentage Diff. & $8.23 \%$ & $13.07 \%$ & $11.02 \%$ & $12.06 \%$ & $16.03 \%$ & $20.80 \%$ & $19.64 \%$ \\
Students t-test & Not Sig. & Not Sig. & Not Sig. & Not Sig. & Not Sig. & Not Sig. & Not Sig. \\
p-Value & 0.735 & 0.613 & 0.753 & 0.681 & 0.541 & 0.444 & 0.480 \\
\hline
\end{tabular}

The standard deviation associated with the viscoelastic strain measurement on the tension face at a series of time points can be seen in Fig. 13. The reinforced beams experience much more consistent viscoelastic behaviour and there is a greater standard deviation observed within unreinforced beams. In Table 6, a comparison is made between the mean viscoelastic strain component on the tension face of unreinforced and reinforced beam groups. It can be seen that even after 3 weeks of testing, a percentage difference of $39.84 \%$ exists between the viscoelastic strain measured on the tension faces of unreinforced and reinforced beams. Statistical Student's t-tests have shown that, at this point, the percentage difference is not statically significant. The difference is not statistically significant until after week 15 with a percentage difference of $44.90 \%$. This percentage difference continues to increase to a maximum of $54.33 \%$ at week 71 as seen in Table 6 and is still increasing with time. This indicates a reduced creep rate on the tension faces of reinforced beams as a result of the reinforcement.

Fig. 13. Mean and standard deviation of the viscoelastic strain $(\mu \varepsilon)$ measured on the tension faces of the unreinforced and reinforced groups at a series of time points $\left(\varepsilon_{\mathrm{ve}}\right)$.

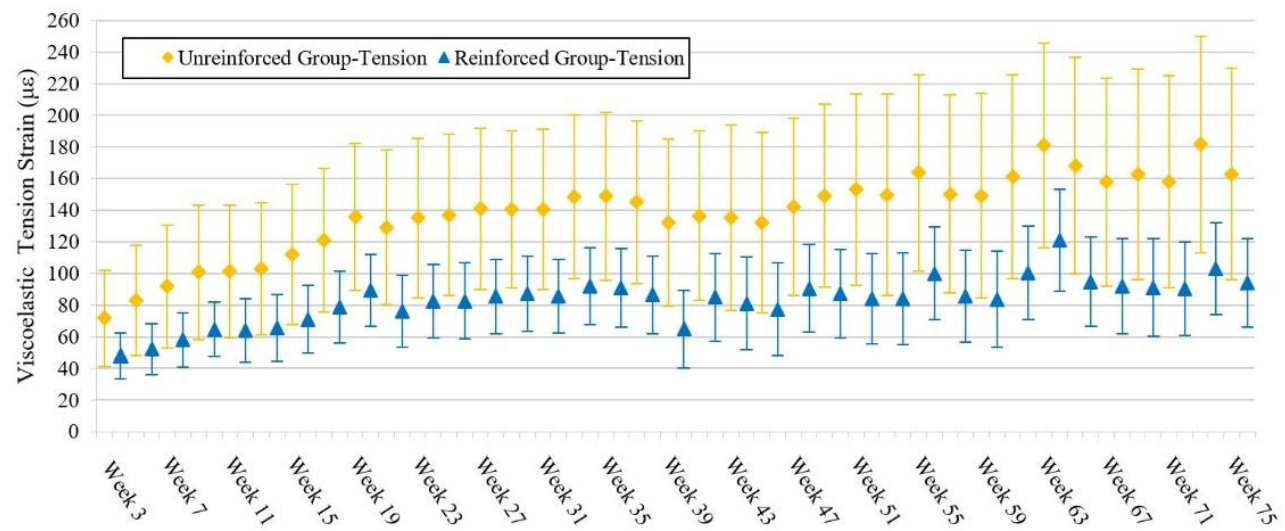

Table 6. Average viscoelastic strain (standard deviation) on tension face of the unreinforced and reinforced groups at a series of time points $\left(\varepsilon_{v e}\right)$.

\begin{tabular}{|c|c|c|c|c|c|c|c|}
\hline Group-Tension & Week 3 & Week 7 & Week 15 & Week 31 & Week 47 & Week 55 & Week 71 \\
\hline Unreinforced & $71.77(30.43)$ & $91.79(38.90)$ & $112.08(44.44)$ & $140.56(50.56)$ & $142.33(56.07)$ & $163.72(62.00)$ & $157.94(67.22)$ \\
\hline Reinforced & $47.93(14.43)$ & $58.02(17.06)$ & 70.98 (21.29) & $85.66(23.47)$ & 90.56 (27.77) & $100.03(29.30)$ & 90.47 (29.50) \\
\hline Percentage Diff. & $39.84 \%$ & $45.08 \%$ & $44.90 \%$ & $48.54 \%$ & $44.46 \%$ & $48.30 \%$ & $54.33 \%$ \\
\hline
\end{tabular}




\begin{tabular}{lccccccc} 
Students t-test & Not Sig. & Not Sig. & Sig. & Sig. & Sig. & Sig. & Sig. \\
p-Value & 0.086 & 0.057 & 0.048 & 0.023 & 0.049 & 0.030 & 0.032 \\
\hline
\end{tabular}

382 The short-term behaviour of FRP-reinforced timber beams has been widely investigated. This study focuses on the long383 term behaviour of these elements and investigates the influence of the reinforcement on the viscoelastic creep response. A 384 test procedure has been designed to ensure that other factors known to influence the creep behaviour of timber elements 385 do not prevent valid comparisons between the response of reinforced and unreinforced beams. These factors are the differences in mechanical properties of the timber due to the natural variability in timber properties, differences in moisture content and temperature due to the climatic conditions and differences in the stress level due to the applied loads.

The variability in the timber properties has been minimised by creating matched groups, statistically equal in terms of unreinforced bending stiffness. The climate conditions throughout the test remained at a constant temperature and relative humidity. As a result, additional moisture content, temperature, mechano-sorptive creep and swelling/shrinkage effects were avoided. Each beam was subjected to a specific applied load to induce a bending stress of 8 MPa on the compression face. This ensured that the timber stress levels in both the unreinforced and reinforced beam groups were closely matched. reinforcement in modest quantities can greatly increase the short-term flexural stiffness of glued laminated beams. An average increase in local bending stiffness of $16.3 \%$ was observed for a moderate percentage reinforcement of $1.85 \%$. The results demonstrated the suitability of this material for timber reinforcement applications.

The long-term deflection results have shown an overall decrease in the total deflection (elastic deflection + viscoelastic deflection) of reinforced beams due to the FRP reinforcement. However, when examining the long-term creep deflections, it has been shown that there is no statistically significant reduction in relative viscoelastic creep deflection when comparing both the unreinforced and reinforced beam groups loaded to a common maximum compressive bending stress. The influence of the reinforcement on the total creep response is indirect and is due to an increase in elastic stiffness. This indicates that the current creep modification factors provided for solid or engineered wood products in Eurocode 5 [14] may be adequate in describing the creep behaviour of FRP reinforced beams under Service Class 1 conditions. The final deflection of FRP-reinforced timber beams may be calculated using the current Eurocode 5 procedures using the composite elastic stiffness of the reinforced beam. While this finding is valid for the current test programme, additional work is required to determine its validity in general. The influence of the timber species, FRP material and reinforcement percentage on the creep deflection behaviour requires further study. For other service class conditions, the influence of 
different timber moisture contents also requires investigation. Additionally, the applied stress level requires attention and the creep response at higher stress levels should be examined so that the cut-off point in relation to tertiary creep can be determined. The viscoelastic behaviour of unreinforced timber elements has been shown to be susceptible to tertiary creep or creep rupture at stress levels in excess of $55 \%[15,16]$. The use of FRP materials may delay the onset of creep rupture and should be examined.

The viscoelastic mid-span longitudinal strains on the compression faces of both the unreinforced and reinforced beams were similar and no statistically significant difference was observed, as expected from the experimental design. In comparison, on the tension face, a statistically significant reduction in viscoelastic strain in the reinforced group relative to the unreinforced group was found. This reduction in strain rate is due to the change in the stress distribution within the timber when reinforced.

The methodology described in this paper is being used to investigate the influence of other climatic conditions. Two matched groups (one unreinforced and one reinforced) are under creep testing in a controlled variable climate condition to examine and quantify the effect of FRP reinforcement on mechano-sorptive and swelling/shrinkage behaviour of timber elements, which occurs under Service Class 2/Service Class 3 conditions with changing moisture content. This will be reported in a future publication.

\section{ACKNOWLEDGEMENT}

This work has been carried out as part of the project entitled 'Innovation in Irish Timber Usage' (project ref. 11/C/207) funded by the Department of Agriculture, Food and the Marine of the Republic of Ireland under the FIRM/RSF/COFORD scheme. The authors would also like to thank ECC Teo. (Earrai Coillte Chonnacht Teoranta) for supplying the timber used in this project. The contribution of the technical staff of the College of Engineering and Informatics, NUIG, in particular, Peter Fahy, Colm Walsh and Gerard Hynes, is acknowledged.

\section{REFERENCES}

[1] J.R. Gilfillan, S.G. Gilbert, G.R.H. Patrick, The improved performance of home grown timber glulam beams using fibre reinforcement, J. Inst. Wood Sci. 15 (2001) 307-317.

[2] H.R. Valipour, K. Crews, Efficient finite element modelling of timber beams strengthened with bonded fibre reinforced polymers, Constr. Build. Mater. 25 (2011) 3291-3300. doi:10.1016/j.conbuildmat.2011.03.017.

[3] G. Raftery, A. Harte, Low-grade glued laminated timber reinforced with FRP plate, Compos. Part B Eng. 42 (2011) 724-735. doi:10.1016/j.compositesb.2011.01.029. 
[4] J.F. Brady, A.M. Harte, Prestressed FRP flexural strengthening of softwood glue-laminated timber beams, World Conf. Timber Eng. 2008. (2008).

[5] A.M. Harte, P. Dietsch, Reinforcement of timber structures: A state-of-the-art report., Shaker Verlag GmbH, Germany, 2015.

[6] W. Lu, Z. Ling, Q. Geng, W. Liu, H. Yang, K. Yue, Study on flexural behaviour of glulam beams reinforced by Near Surface Mounted (NSM) CFRP laminates, Constr. Build. Mater. 91 (2015) 23-31. doi:10.1016/j.conbuildmat.2015.04.050.

[7] K.-U. Schober, A.M. Harte, R. Kliger, R. Jockwer, Q. Xu, J.-F. Chen, FRP reinforcement of timber structures, Constr. Build. Mater. 97 (2015) 106-118. doi:10.1016/j.conbuildmat.2015.06.020.

[8] S. Franke, B. Franke, A.M. Harte, Failure modes and reinforcement techniques for timber beams - State of the art, Constr. Build. Mater. 97 (2015) 2-13. doi:10.1016/j.conbuildmat.2015.06.021.

[9] I.R. Kliger, R. Haghani, M. Brunner, A.M. Harte, K.U. Schober, Wood-based beams strengthened with FRP laminates: improved performance with pre-stressed systems, Eur. J. Wood Wood Prod. 74 (2016) 319-330. doi:10.1007/s00107-015-0970-5.

[10] L.D. Armstrong, R.S. Kingston, Effect of moisture changes on creep in wood, Nature, London. 185 (1960) $862-$ 863. doi:10.1038/185862c0.

[11] L.D. Armstrong, R.S.T. Kingston, The effect of moisture content changes on the deformation of wood under stress, Aust. J. Appl. Sci. 13 (1962) 257-276.

[12] A. Mårtensson, Creep behavior of structural timber under varying humidity conditions, J. Struct. Eng. 120 (1994) $2565-2582$.

[13] C. Bengtsson, R. Kliger, Bending creep of high-temperature dried spruce timber, Holzforschung. 57 (2003) $95-$ 100. doi:10.1515/hf.2003.015.

[14] CEN, EN 1995-1-1. Eurocode 5: Design of timber structures - Part 1-1: General - Common rules and rules for buildings, Comité Européen de Normalisation, Brussels, Belgium, 2009.

[15] J. Senft, S. Suddarth, An analysis of creep-inducing stress in Sitka spruce, Wood Fiber Sci. 2 (1971) 321-327.

[16] T. Toratti, Creep of timber beams in a variable environment, Laboratory of Structural Engineering and Building Physics, Helsinki University of Technology, Finland, 1992. 
[17] R.W. Davidson, The influence of temperature on creep in wood, For. Prod. J. 12 (1962) 377-381.

[18] L.D. Armstrong, Deformation of wood in compression during moisture movement, Wood Sci. 5 (1972) 81-86.

[19] S. Hering, P. Niemz, Moisture-dependent, viscoelastic creep of European beech wood in longitudinal direction, Eur. J. Wood Wood Prod. 70 (2012) 667-670. doi:10.1007/s00107-012-0600-4.

[20] D.G. Hunt, The prediction of long-time viscoelastic creep from short-time data, Wood Sci. Technol. 38 (2004) 479-492. doi:10.1007/s00226-004-0244-6.

[21] P. Gressel, Prediction of long-term deformation behaviour from short-term creep experiments, Holz Als Roh-Und Werkst. 42 (1984) 293-301. doi:10.1007/BF02608938.

[22] R. Kliger, M. Al-Emrani, M. Johansson, R. Crocetti, Strengthening timber with CFRP or steel plates - Short and long-term performance, in: Proc. 10th World Conf. Timber Eng. 2008, June 2, 2008 - June 5, 2008, Miyazaki, Japan, 2008: pp. 414-421.

[23] N. Plevris, T. Triantafillou, Creep behavior of FRP-reinforced wood members, J. Struct. Eng. 121 (1995) 174-186. doi:10.1061/(ASCE)0733-9445(1995)121:2(174).

[24] M. Yahyaei-Moayyed, F. Taheri, Experimental and computational investigations into creep response of AFRP reinforced timber beams, Compos. Struct. 93 (2011) 616-628. doi:10.1016/j.compstruct.2010.08.017.

[25] W.G. Davids, H.J. Dagher, J.M. Breton, Modeling creep deformations of FRP-reinforced glulam beams, Wood Fiber Sci. 32 (2000) 426-441.

[26] G. Raftery, A. Harte, Material characterisation of fast-grown plantation spruce, Struct. Build. 167 (2014) 380-386. doi:10.1680/stbu.12.00052.

[27] J.R. Gilfillan, S.G. Gilbert, G.R.H. Patrick, The use of FRP composites in enhancing the structural behavior of timber beams, J. Reinf. Plast. Compos. 22 (2003) 1373-1388. doi:10.1177/073168403035583.

[28] CEN, EN 14080. Timber structures - Glued laminated timber and glued solid timber - Requirements, Comité Européen de Normalisation, Brussels, Belgium, 2013.

[29] R. Parnas, M.T. Shaw, Q. Liu, Basalt fiber reinforced polymer composites, New Engl. Transp. Consortium. Proj. Rep. No. 03-7 NETCR63. (2007).

[30] V. Lopresto, C. Leone, I. De Iorio, Mechanical characterisation of basalt fibre reinforced plastic, Compos. Part B Eng. 42 (2011) 717-723. 
[31] D. Yeboah, S. Taylor, D. McPolin, R. Gilfillan, Pull-out behaviour of axially loaded Basalt Fibre Reinforced Polymer (BFRP) rods bonded perpendicular to the grain of glulam elements, Constr. Build. Mater. 38 (2013) 962969. doi:DOI 10.1016/j.conbuildmat.2012.09.014.

[32] C. O’Neill, D. McPolin, S.E. Taylor, A.M. Harte, C. O’Ceallaigh, K.S. Sikora, Timber moment connections using glued-in basalt FRP rods, Constr. Build. Mater. 145 (2017) 226-235. doi:10.1016/j.conbuildmat.2017.03.241.

[33] MagmaTech Limited, Rockbar-Corrosion resistant basalt fibre reinforcing bars, Tech. Data Sheet, Accessed, 11/10/2014. (2014). www.magmatech.co.uk.

[34] ISO, 10406-1. Fibre-reinforced polymer (FRP) reinforcement of concrete Test methods Part 1: FRP bars and grids, ISO, Geneva, Switzerland, 2015.

[35] CEN, EN 408. Timber structures - Structural timber and glued laminated timber - Determination of some physical and mechanical properties, Comité Européen de Normalisation, Brussels, Belgium, 2014.

[36] R.W. Runyen, D.W. Dinehart, S.P. Gross, W.G. Dunn, Creep behavior of wood I-joists with web openings exposed to normal and low relative humidity conditions., in: Proc. World Conf. Timber Eng. 2010, WCTE 2010, June 20, 2010 - June 24, 2010, Trento, Italy, 2010.

[37] C. Bengtsson, Mechanosorptive Creep in Wood - Experimental studies of the influence of material properties, Chalmers University of Technology, Goteborg, Sweden, 1999. 